\section{Drawing a double-edged sword}

\author{
Harvey R. Colten
}

WHILE cruising the Mediterranean aboard the Prince of Monaco's yacht, Charles Richet and Paul Portier began a set of experiments that led to their discovery of anaphylaxis, a sudden devastating immunological reaction, and to the Nobel Prize in Physiology or Medicine for Richet in 1913 (see illustration on next page). The prevailing wisdom at the time was that immunization with small amounts of toxins gave protection against any future encounter (phylaxis), so they were surprised to find that animals previously exposed to sublethal quantities of the toxins from the jellyfish Physalia or sea anemone Actinaria were so sensitive to the toxin that they died shortly after receiving even a tiny dose ${ }^{1}$. Within a year Arthus described what he believed to be a cutaneous manifestation of anaphylaxis resulting from repeated intradermal injections of horse serum ${ }^{2}$. The Arthus reaction and anaphylaxis were later shown to be quite distinct pathophysiologically, however, and to be examples of a much broader set of immunological reactions. These were early indications that inflammation is a dual weapon - one that is critical for host defence, but also a potent trigger of serious, even fatal, disease.

Ninety years on from the observations of Richet, Portier and Arthus, the techniques of modern biology are being employed to dig deeper into the complex systems that mediate inflammation. A spate of papers ${ }^{3-6}$ over the past months attests to the level of interest in the problem. All of them employ targeted gene disruption by homologous recombination. And all of them bear on what I see as a central issue in this field. Is inflammation primarily triggered by cellular immunoglobulin $\mathrm{Fc}$ receptors or by complement activation?

In these new experiments, deletions of cell-surface receptors for immunoglobulins ${ }^{3-5}$ or deletions of a specific class of immunoglobulin ${ }^{6}$ were used to define

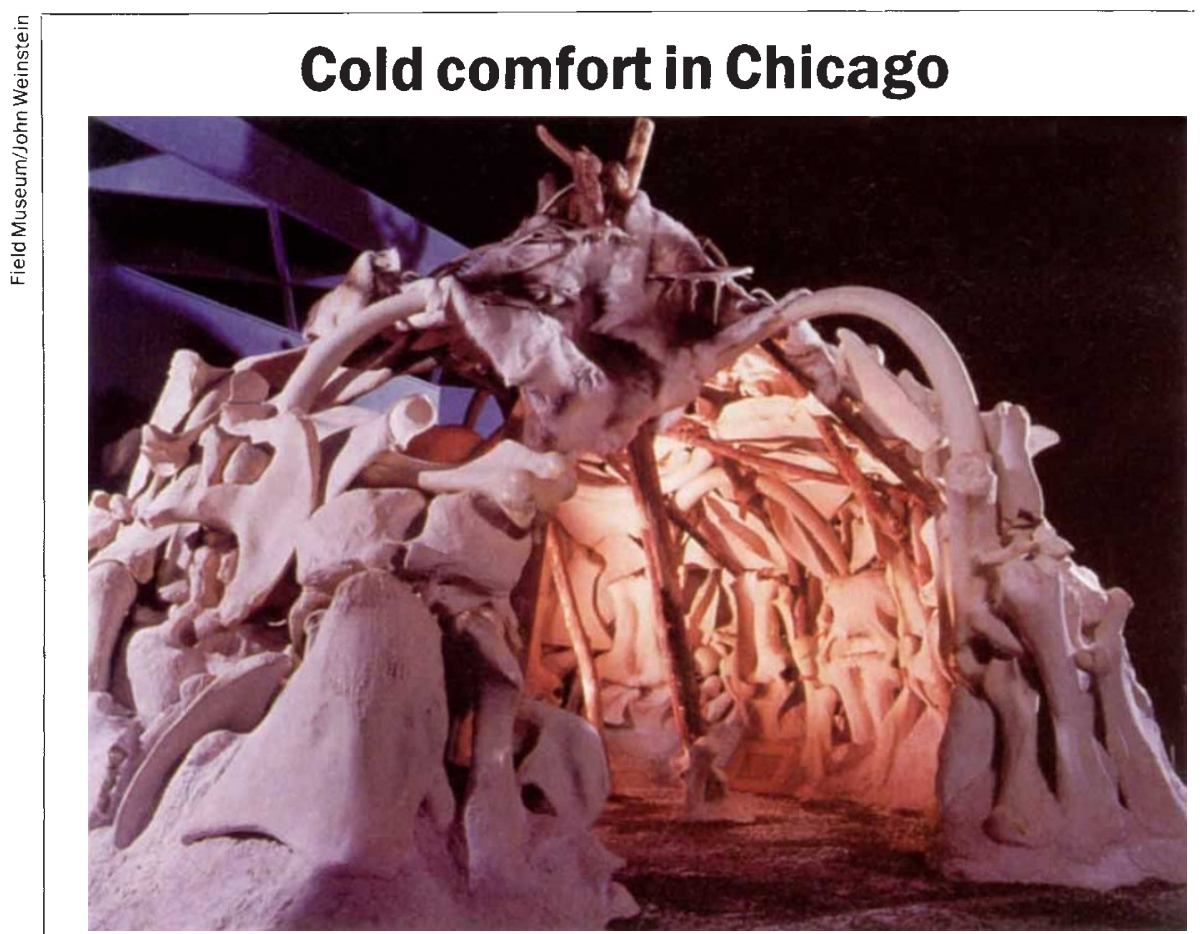

THIS life-sized reconstruction of a mammoth-bone hut is just one of the spectacular items on show at Teeth, Tusks and Tar Pits, a permanent exhibition opening on 12 November at the Field Museum of Natural History in Chicago. The exhibition adds thematically to the DNA to Dinosaurs hall which opened on 11 June, taking the history of life from the end of the Mesozoic 65 million years ago to the present day. As well as the mammoth hut and several other ice-age exhibits appropriate for a city in the northern United States, Teeth. Tusks and Tar Pits features the minutely detailed fossils from the Eocene Green River formation of Wyoming. Displays on the evolution of humanity will excite particular interest, given the prominence of creationist remarks in the (admittedly self-selected) sample of comments pinned by visitors to bulletin boards at intervals throughout DNA to Dinosaurs. The two exhibitions have a combined area of 23,000 square feet, so visitors are advised to wear comfortable shoes and be prepared to take a whole day to get around them.

the essential components of hypersensitivity reactions. Receptors for immunoglobulin on mast cells (and on other cells of haematopoietic origin) are multimeric complexes derived from several genes. So by targeting the common subunit $\gamma$-gene, Sylvestre and Ravetch ${ }^{3}$ and Takai et al. ${ }^{4}$ were able to delete both $\mathrm{IgE} F \mathrm{Fc}$ (FceRI) and IgG Fc (Fc $\gamma$ RI, Fc $\gamma$ RIII) receptors; likewise, Dombrowicz et al. ${ }^{5}$ selectively deleted the $\operatorname{IgE} F \mathrm{c}$ receptor by targeting its specific $\alpha$-chain. In both strains of mice, anaphylactic reactions to systemic or cutaneous antigen stimulation were abrogated or markedly attenuated.

In contrast, Oettgen et al. ${ }^{6}$ showed that antigenic challenge of mice deficient in IgE immunoglobulin led to systemic anaphylaxis indistinguishable from that observed in wild-type mice. These data back up earlier work ${ }^{7,8}$ that defined the IgG immunoglobulins as capable of triggering anaphylaxis. Among the $\operatorname{IgG}$ antibodies that generate this hypersensitivity reaction are some that activate the complement cascade and others (noncomplement fixing) that bind to tissue mast cells ${ }^{7}$. That the latter subclass of antibody is more important in systemic anaphylaxis is suggested by Oettgen and colleagues' finding that complement depletion of the IgE-deficient mice had little or no effect on the response.

Sylvestre and Ravetch ${ }^{3}$ showed that the Arthus reaction is also markedly attenuated in animals deficient in the $\mathrm{FcR} \gamma$ chain, and that complement depletion abrogates the residual inflammatory. response. Ravetch ${ }^{9}$ has compied results from these studies to develop a concept of the 'primacy' of Fc-receptor interactions with immune complex (antigen-antibody) which triggers the subsequent cellular/ humoral events of inflammation. In his view, complement has a secondary role by amplifying the Fc-triggered response.

This stands in contrast to the idea that immune-complex activation of the complement cascade is the main event triggering IgG-mediated hypersensitivity reactions. As outlined below, the relative importance of these two mechanisms is a function of the immune status of the organism. Activation of complement generates complement-derived polypeptides (such as C3a, C3b, C3bi, C5a) that interact with their cognate cellular receptors. The result is increased vascular permeability, smooth-muscle contraction, altered expression of cell-surface receptors, directed migration and mediator release from leukocytes, all components of inflammatory reactions.

Oettgen et al. conclude that complement plays little or no part in these $\operatorname{IgG}$ (non-IgE)-mediated hypersensitivity reactions by 'depleting' complement in their knockout mice with cobra venom factor. Sylvestre and Ravetch also compare the effect of cobra venom depletion 